\title{
LAS VIRTUDES DEL MARXISMO
}

\author{
Francisco Fernández Buey
}

\section{LAS VIRTUDES DEL MARXISMO*}

En la Historia de la humanidad no hay retroceso voluntario/... y, suponiendo esto la Historia se asemeja a un hombre que camina siempre hacia adelante, movido por un afán tremendo de viajar, para el que no hay posibilidad de retroceso ni de meta. Este es un estado muy interesante.

R. Musil, El hombre sin atributos. I

Empezaré con una declaración de perplejidad para tratar de justificar una argumentación que tal vez parezca paradójica. En los casi treinta años que llevo aceptando invitaciones para hablar sobre marxismo ésta es la primera vez que me convocan bajo un rótulo tan favorable como "las virtudes del marxismo". Desde hace ya muchos años siempre se me habia convocado bajo rótulos en los que aparecía por lo menos la palabra "crisis", cuando no la palabra "hundimiento", o final". etc. Al menos en forma interrogativa. Así es que agradezco mucho, y sentidamente, a los organizadores el gesto optimista y benevolente que han tenido en esta oportunidad.

Como ya esto es una primera paradoja en mi caso quizás no les

* Intervención en una mesa redonda titulada Les virtuts del marxisme organizada por la Fundació Acta, en Barcelona, el 6 de noviembre de 1992 para recordar el 75 aniversario de la revolución rusa. 
extrañe que siga con una segunda. En forma de respuesta a una pregunta: por qué uno que se sigue considerando comunista y marxista, como yo, se siente ahora psíquica $\mathrm{v}$ moralmente mejor, si se me permite hablar así, que en los años 60 y 70 cuando, según se afirma a menudo, el marxismo estaba de moda.

No pretendo que mi respuesta a esta pregunta valga para todo el mundo que se consideró marxista en otro tiempo. Pero es la mía: sencillamente, porque con el final del llamado "socialismo real" se han terminado los dos mayores cánceres de lo que se llamaba marxismo en aquella época: el dogmatismo de tantos intelectuales marxistas sin vivencia de la pobreza y el oportunismo instrumentalizador de tantos funcionarios de los aparatos politicos.

Hoy, en cambio, un socialista o comunista se encuentra a gusto en todos los sentidos de la expresión en compañía de gentes tan distintas pero tan próximas como, pongamos por caso: Ernesto Cardenal, José Maria Valverde, Josep Fortna, Jean Ziegler, Pietro Ingrao, E.P. Thompson, Valentino Gerratana, John Bergen, Julio Anguita o Mario Benedetti, todos los cuales han hecho últimamente declaraciones parecidas a éstas que yo estoy haciendo aquí.

Cojamos el toro por los cuernos. El fin de la experiencia denominada "socialismo real" afecta sin duda, al marxismo. $Y$ afecta también a la idea de socialismo. ¿En qué medida? ¿En qué medida ha quedado afectado el comunismo/socialismo marxista por el fracaso o la derrota de la experiencia soviética?

Contesto. En una medida muy parecida a como quedó afectado el cristianismo de Jesús de Nazaret desde la fusión de un cristianismo con el poder de los emperadores, con el abuso de los papas de Roma y con el establecimiento de la Inquisición. En la misma medida en que quedó afectado el ideario liberal europeo por la represión de las revoluciones obreras de 1848 y de 1871 así como por el doble criterio empleado para juzgar lo que pasaba en las metrópolis y lo que ocurría en las colonias. En la misma medida, en fín, en que quedó afectado el gandhismo por la persistencia del hambre entre las gentes y por la represión violenta de las minorías en la India.

A pesar de los horrores de la Inquisición ha seguido habiendo cristianos en España después de Torquemada y de Fernando 
Valdés. A pesar de la represión de la Commune, ha seguido habiendo liberales en Francia. A pesar de la represión criminal de los movimientos de liberación en la India y en Sudáfrica, ha seguido habiendo liberales en Gran Bretaña. A pesar del hambre y de la violencia institucional vinculada al apellido Gandhi ha seguido habiendo gandhianos en todo el mundo.

Se me dirá que tales comparaciones son odiosas. A lo que contesto que lo son, efectivamente. $Y$ que en estas cosas de los idearios manchados por los crímenes de los poderes, pasa, cuando se compara, lo mismo que con los chistes con protagonista étnico: que dejamos de reirnos cuando se dice que el protagonista es paisano nuestro. Entonces ponemos en duda el sentido del humor de los otros.

Dudo, por lo demás, que se pueda pensar en lo que ha sido y puede ser el socialismo marxista sin introducir comparaciones de estas que nos pemiten ver con distancia la propia historia.

Quisiera dar un paso mas en la misma dirección para intentar contestar a otra pregunta un poco más comprometida. ¿Por qué, a pesar de lo que sabemos, cristianismo, liberalismo, gandhismo, etc.. siguen existiendo como idearios, como movimientos de ideas o como realidades político-sociales? ¿Porqué el hombre es el animal que tropieza dos y hasta tres veces en la misma piedra? Puede ser. Propongo, sin embargo, otra interpretacion. Porque cristianismo, liberalismo, gandhismo, etc., han sido vividos por sectores sociales amplios de poblaciones también amplias como idearios de liberación desdoblados o rotos en el momento en que se convirtieron en ideologías de dominación.

Por eso hace mucho tiempo que hay varios cristianismos, varios liberalismos y varios gandhismos.

"Los ideales tienen extrañas propiedades —escribió Musil en $E l$ hombre sin atributos-: entre otras la de transformarse en su contrario cuando se les quiere seguir escrupulosamente".

Me parece que este principio de explicación de la persistencia de cristianismo, liberalismo o gandhismo vale también para el socialismo marxista entendido como una tradición liberadora o emancipadora. Esta tradición, al materializarse en movimientos his- 
tóricos, concretos, se ha desdoblado y desquiciado hasta romperse. Durante medio siglo el socialismo marxista ha sido al mismo tiempo ideología de una dominación sobre los de abajo e inspiración de las luchas de los de abajo contra la dominación existente. Así en España como en la URSS, en Italia como en China.

Desdoblamiento bajo una misma palabra. De la misma manera que resultaba difícil hacer caer bajo un mismo ideario a Luis Vives y a Torquemada, a Erasmo y a Ginés de Sepúlveda, a Bartolomé de las Casas y a Fernando Valdés, por poner un ejemplo, o asimilar a Einstein con Truman o a Russell con la Thatcher al hablar de liberalismo, por poner otro ejemplo, así también el desdoblamiento del socialismo marxista obliga a distinguir entre Stalin y Trotski, entre Zhanov y Gramsci, entre Ebert y Rosa Luxemburg.

Quisiera hacer seguir de la "odiosa comparación" que acabo de establecer la siguiente conclusión de la misma manera que la persistencia del cristianismo, del liberalismo y del gandhismo como movimientos de liberación se ha debido al ejemplo de cristianos, liberales y gandhianos que sin renunciar a los principios de igualdad, libertad, tolerancia y pacifismo, se enfrentaron abiertamente a la conversión del cristianismo, del liberalismo y del gandhismo en ideologías justificadoras del poder y de la represión, así también la persistencia del socialismo marxista se debe a unos cuantos ejemplos que nadie discute y que al entrar en comparaciones casi nadie encuentra elementos para considerar "odiosas": Marx mismo, desde luego (alabado como economista por The Wall Street Journal de diciembre pasado), Rosa Luxemburg, Antonio Gramsci...

Digo casi nadie, a sabiendas. Hay gentes que consideran que la degradación del socialismo marxista ya estaba in nuce en Marx. Como hay gentes que estiman que el convencimiento mesiánico de Jesús de Nazaret tenía que conducir a la Inquisición, y como hay gentes que ven en Adam Smith la preformación de todas las injusticias del capitalismo liberal. No creo que sea necesario probar la "santidad" de los padres fundadores de nada. Para el tipo de argumento que intento comunicarles seguramente basta con admitir una intuición del poeta León Felipe sobre "el hombre que tenía una doctrina", la cual creció, creció y creció hasta convertirse en templo, etc. León Felipe concluye esa intuición con un exabrupto 
no muy poético: el que tenga una doctrina que se la coma antes de que su conversión en templo (en iglesia) acabe comiéndose a los partidarios de la doctrina.

Aunque admiro mucho el talante moral de León Felipe, tengo que confesar que no veo todavía a nuestra humanidad con capacidad para poner en práctica tamaño acto de desideologización de los comportamientos de la especie. Ni en el sentido bondadoso de León Felipe ni en el sentido interesado de los sociólogos y teóricos del final de las ideologías. Por lo que yo sé, toda teoría del final de las ideologías es la premonición de una nueva fase histórica hiperideológica. El que no lo parezca - porque las nuevas ideologías son siempre recomposición de antiguas ideologías que se afirman contra las ideologías del presente- es sólo consecuencia del déficit de fomación histórica de la mayoría de los sociólogos.

Deduzco de lo dicho que, a pesar de los crímenes cometidos en nombre del socialismo desde que el socialismo se hizo poder, el impulso ético del socialismo marxista seguirá teniendo un papel importante entre las gentes explotadas y oprimidas del final del siglo XX. Es verdad que esto obligará a los socialistas marxistas del final de siglo a una reconsideración general del ideario, a algunas rectificaciones de lo que fue el concepto tradicional de socialismo; a hacer la propia reforma: a hacerse laicos en el comportamiento cotidiano. Mientras tanto el socialismo marxista va a vivir un momento malo seguramente caracterizado por el florecimiento de numerosas "órdenes" o corrientes incoordinadas que tratarán de recuperar la sustancia de los orígenes y de adaptarse a las novedades de un mundo en el que volverán con fuerza los enfrentamientos intercapitalistas.

Permitanme argumentar esta previsión.

Muchas, muchísimas cosas han cambiado en el mundo desde que Marx escribió El Capital. Pero hay al menos dos o tres hechos nuevos que son decisivos para contestar a la pregunta sobre qué puede significar ser marxistas y socialistas al final del siglo $X X$. Uno de estos hechos es naturalmente, Ia derrota de todas las revoluciones socialistas empezando por la revolución rusa de 1917. El otro hecho suele tenerse menos en cuenta o no se relaciona frecuentemente con éste: es la magnitud de la crisis ecológica a la 
que la civilización industrial-capitalista está conduciendo al planeta Tierra. El tercer hecho es sólo una novedad a medias: la dimensión mundial del hambre y de la miseria material en esta plétora miserable en la que estamos viviendo.

Mi hipótesis es que no puede haber ningún marxismo renovado para este fin de siglo sin un análisis pormenorizado de las causas de la derrota en el plano social. Tampoco podrá haberlo sin la estimación crítica de las razones por las cuales la fusión entre capitalismo e industrialismo está conduciendo a un desastre medioambiental de dimensiones desconocidas en la historia de la humanidad, la cual, además, se complica con la crisis demográfica y las hambrunas que afectan a dos tercios de la población mundial.

Hay ya aportaciones historiográficas suficientes para un análisis de los motivos de la derrota. Las obras de Carr, Lewin, Maidanik, Mevdevev, Procacci, Nove, Zinoviev, Carrere d'Encausse, etc. aportan lo esencial para esta explicación. Importa poco que algunos de estos análisis no sean marxistas o tengan escasamente que ver con el marxismo. Al fin y al cabo Marx se inspiró en autores que estaban en las antípodas desde el punto de vista político-social.

También empieza a haber conciencia de la importancia de la interrelación entre lo económico y lo ecológico en la crisis medioambiental actual. Y particularmente entre marxistas críticos. La obra de Barry Commoner es un ejemplo. Pero no es el único. Se puede mencionar también a Laura Conti, a Dario Paccino, a algunos de los autores del Manifiesto ecosocialista, a los editores americanos de Capitalism, Nature Socialism. Y, naturalmente, a Manuel Sacristán entre nosotros.

Tengo que reconocer que el análisis crítico de las experiencias históricas y la conciencia de la interrelación entre persistencia del capitalismo y crisis ecológica no ha cuajado todavía en un cuerpo de creencias ampliamente compartidas, que es lo que hizo del socialismo marxista en otro tiempo una tradición ideal. Cuando se sale de una derrota se necesita tiempo para recuperarse. Tal es nuestro caso. Pero no me cabe duda alguna sobre la solidez de los mimbres con que se va a construir el nuevo cesto. Lo más difícil 
en este momento es esbozar programas alternativos para una sociedad de iguales, mujeres y varones blancos y negros, adultos y niños, heterosexuales y homosexuales, una sociedad de iguales socialmente en la diversidad cultural, en una tierra habitable; programas económicos, esto es, que reduzcan las desigualdades tremendas existentes en el mundo e integren las necesidades medioambientales. La reciente batalla de Río de Janeiro es una muestra palpable de las dificultades existentes en este campo.

Esta última consideración nos introduce en un ámbito que rebasa el impulso moral o ético del socialismo marxista. Si he puesto tanto el acento en la persistencia del socialismo marxista como filosofia moral como filosofía de la liberación, es por la necesidad de corregir el principal defecto de los marxismos que imperaron en los años sesenta y setenta: el cientificismo, la ingenua creencia en una superación absoluta de la utopía en la ciencia social. Pero es cierto que el socialismo marxista ha tenido siempre una vocación científica, la intención de hacer científicamente razonable la pasión emancipadora o liberadora de los de abajo. Conviene preguntarse, por tanto, qué tiene el socialismo marxista que decirnos a las gentes de hoy, si es que tiene todavía algo que decirnos. Pues sólo en el caso de que aún tuviera el marxismo cosas esenciales que decirnos y no hubiera surgido otra teoría alternativa de la revolución estaría justificado apostar por la renovación de esta tradición.

En mi opinión, varias de las tendencias en curso en el mundo actual confirman apreciaciones importantes de Marx y de los marxistas críticos sobre la evolución del capitalismo. Enumeraré algunas: 1/La mundialización del sistema económico: su conversión acelerada en sistema-mundo; 2 /La concentración de capitales y el impulso histórico hacia formas monopolistas alternantes con las guerras comerciales; 3 /EI papel del complejo científico-técnico en el proceso productivo del capitalismo desarrollado; 4/El proceso de oligarquización de las democracias como consecuencia de la mercantilización creciente de todas las relaciones entre los hombres; 5/La persistencia del trabajo alienado más allá de la reducción de la jornada de trabajo de los obreros; 6/La evolución del fetichismo de la mercancía y, en particular, de la mercancía hombre en el proceso de asalarización del trabajo; $7 / \mathrm{El}$ aumento de las 
diferencias sociales en el ámbito mundial; 8/La importancia de las crisis de sobreproducción en el sistema capitalista mundial; $9 /$ La necesidad de intervención estatal para corregir las fluctuaciones anárquicas de la sociedad y la destrucción de la naturaleza en la industria y la agricultura de las economías de mercado.

La historia de los últimos setenta y cinco años ha puesto de manifiesto que Marx estaba equivocado en otras cosas. Por ejemplo, en su idea de que las contradicciones entre apropiación privada de los medios de producción y crecimiento de las fuerzas productivas empuja hacia el socialismo (hoy habría que decir: no sólo); por ejemplo, en su caracterización de la sociedad alternativa como un reino de la libertad en el que serían satisfechas todas las necesidades de los hombres (hoy habría que decir: con escasa atención al expolio de la naturaleza y a la distribución intergeneracional de los recursos escasos no renovables). Hay, además, en la obra de Marx insuficiencias conceptuales que han dado lugar a ambigüedades, y éstas a barbaridades históricas: por ejemplo, en la caracterización del estado; por ejemplo, en la discusión con Bakunin sobre la dictadura del proletariado; por ejemplo en el análisis de la relación entre nacionalismo e internacionalismo de los de abajo.

A pesar de estos errores e insuficiencias en el plano teórico (y sin olvidar las correcciones que el sistema capitalista ha ido introduciendo en respuesta a las criticas del socialismo marxista: toda teoría seria de la historia aporta más por el impulso positivo de su pars destruens que por lo que postula que hay que construir en su propio nombre), es un hecho universalmente reconocido que el marxismo crítico sigue siendo en el mundo de hoy: 1/elemento importante (junto con otros, desde luego) de lo que en los países latinoamericanos los de abajo llaman filosofia de la liberación 2/ interlocutor constante en el seno de los principales movimientos sociales alternativos (feminismo, ecologismo, pacifismo, de objeción, de defensa de los derechos humanos, religiosos de base, etc.) que existen en países industrialmente desarrollados.

Concluyo. La tendencia o aspiración al socialismo es una tradición milenaria del género humano. El marxismo ha sido la más potente de sus formas modernas. No es creíble que esta tradición vaya a desaparecer ahora, en la plétora miserable en que vivimos. 
La renovación de la tradición socialista, tanto en los países ricos como en los países pobres de un sistema único, se llevará a cabo, si cuaja, en diálogo, en diálogo crítico, desde luego, con aquella que fue su forma más sólida durante tantas décadas.

Digitalizado por Biblioteca "P. Florentino Idoate, S.J." Universidad Centroamericana José Simeón Cañas 